\title{
Efeitos da interação solo-estrutura em edifícios de aço sobre fundação superficial
}

\author{
Renan Moura Guimarães ${ }^{2}$, Alex Sander Clemente de Souza ${ }^{1^{*}}$ e Silvana De \\ Nardin ${ }^{1}$, \\ ${ }^{1}$ Prof. Dr. do Programa de Pós-graduação em Estruturas e Construção Civil \\ da Universidade Federal de São Carlos, alex@ufscar.br \\ ${ }^{2}$ Mestre em Estruturas e Construção Civil pela Universidade Federal de \\ São Carlos
}

\section{Effects of soil-structure interaction in steel building on surface foundation}

\section{Resumo}

Este trabalho apresenta um estudo comparativo entre diferentes edificios em aço sobre fundação do tipo sapatas com a finalidade de analisar a influência da interação solo-estrutura (ISE) nos recalques e nos esforços solicitantes. Foram dimensionadas 5 estruturas e suas respectivas fundações, variando o número de pavimentos e tipos de contraventamentos. As estruturas foram analisadas de forma convencional considerando o solo indeformável e considerando a deformabilidade do solo por meio de coeficientes de reações aplicando a Hipótese de Winkler. Foram analisados os resultados de reações de apoio e momentos fletores na base dos pilares, coeficientes de estabilidade global $B_{2}$, deslocamentos laterais, recalques e também a variação dos esforços de compressão axial e momentos fletores ao longo da altura dos edifícios.

Palavras-chave: Interação solo-estrutura, estruturas metálicas, fundações

\begin{abstract}
This work presents a comparative study between different steel structures on a single-footing foundation with the purpose of analyzing the influence of the soil-structure interaction (SSI) on soil displacements and stresses. Five structures and their respective foundations were designed, varying the number of floors and types of bracing. The structures were analyzed in a conventional way considering rigid base and considering the deformability of the soil by means of reaction coefficients applying the Winkler Hypothesis (SSI). Were analyzed the results of base reactions and bending moments at the base of the columns, global stability coefficients $\mathrm{B}_{2}$, lateral displacements, soil displacements and also the variation of the axial compression forces and bending moments along the height of the buildings.
\end{abstract}

Keywords: $\quad$ soil-structure interaction, steel structures, foundations

\footnotetext{
* autor correspondente
} 


\section{Introdução}

Uma das etapas iniciais da construção de um edifício é a concepção dos projetos, dentre eles o projeto de estruturas e o das fundações. O que ocorre na atualidade é que ambos os projetos são desenvolvidos separadamente e, por não haver uma interface entre os projetistas estrutural e de fundações, a edificação acaba sendo dividida em superestrutura, que é a parte acima do solo, e infraestrutura, que é a parte enterrada (IWAMOTO, 2000). Com isso, no geral, a interação entre o solo e a estrutura (ISE) não é considerada. Sendo assim, o solo é tido como uma base fixa e indeformável pelo projetista de estruturas que, com essa hipótese, analisa as distribuições dos esforços normais, deformações e momentos, e a partir disso dimensiona a estrutura. Porém essa hipótese pode divergir significativamente da realidade pois o solo é deformável e essa deformabilidade pode alterar as condições de apoio e gerar esforços e recalques diferentes daqueles obtidos com a análise convencional, ou seja considerando o solo indeformável.

As edificações, com relação à análise estrutural, podem ser definidas como um sistema constituído por três componentes, sendo eles a superestrutura, a infraestrutura e o solo de fundação, como pode ser observado na Figura 1.

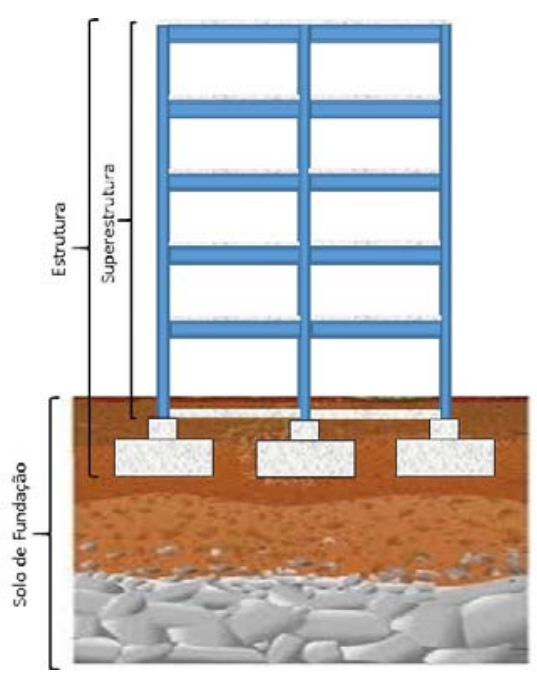

Figura 1 - Elementos que compõem a estrutura de forma global

Enquanto a superestrutura é constituída por lajes, vigas e pilares, responsáveis pela transmissão das ações para a fundação, a infraestrutura liga a superestrutura ao solo, sendo responsável pela transferência dos carregamentos, e o solo de fundação, por sua vez, absorve os esforços da superestrutura garantindo o equilíbrio global do 
sistema (CRESPO, 2004). A interação solo-estrutura nada mais é do que o mecanismo de interação entre esses três componentes.

Tem-se investigado diferentes formas ou procedimentos para representar o solo e a fundação na análise estrutural, por exemplo, podem ser utilizadas molas elásticas distribuídas na interface estrutura-solo, para representar as características do solo. Dessa maneira, o coeficiente da mola em questão está relacionado com a deformação do solo, e pode ser determinado a partir de correlações com o seu módulo de elasticidade.

Vários autores têm se dedicado a investigação do efeito da interação solo estrutura sobre a distribuição de esforços e no dimensionamento dos elementos estruturais, com destaque para: HOLANDA JR. (1998), REIS (2000), GONÇALVES (2011) (2004) e TESTONI (2013). Vale registrar que a maioria desses trabalhos foca sua análise em edifícios de concreto armado.

Outra linha de pesquisa busca o desenvolvimento de procedimentos e ferramentas numéricas para a análise da interação solo-estrutura. Silva e Coda (2010), Soares e outros (2010) e Silva (2014) tem trabalho neste sentido sendo possível identificar diversos modelos de simulação da interação solo-estrutura.

O modelo mais simples e direto é o modelo de Winkler. Trata-se de um método simplificado para consideração da deformação do solo, onde a reação em qualquer ponto do solo é proporcional à deformação neste ponto. A descontinuidade do solo não é considerada, sendo este fator uma das principais críticas ao método. A Hipótese de Winkler tem como grande vantagem a facilidade e rapidez de aplicação e serve como ponto inicial para uma estimativa rápida dos efeitos da deformação do solo nas estruturas. Outra grande vantagem é a dispensa de utilização de grandes recursos computacionais ou necessidade de conhecimento de muitos parâmetros do solo. Deste modo, a Hipótese de Winkler é um dos mais utilizados em pesquisas na área da interação solo-estrutura devido principalmente à sua simplicidade e resultados satisfatórios. Alguns autores que utilizaram a Hipótese de Winkler foram Mendonça (2012), Kocak (2000), Gerolymos (2005), Aron (2012) e Antoniazzi (2011), Colares (2006), MENDONÇA et al. (2015). 
A Figura 2 apresenta o esquema utilizado para formulação do método de Winkler onde o solo sob uma área carregada é substituído por um conjunto de molas lineares cuja rigidez relaciona a pressão no solo e o recalque resultante - Equação 1.

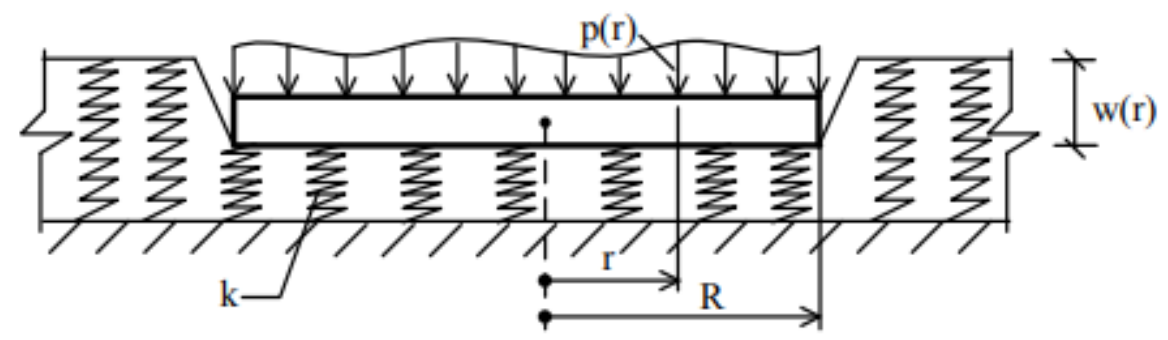

Figura 2 - Modelo esquemático de Hipótese de Winkler

$$
P(r)=K_{v} w(r) \text { Equação } 1
$$

$P(r)$ - Pressão aplicada ao solo pelo elemento de fundação

$K_{v}$ - Coeficiente de reação vertical

$w(r)-$ Recalque

Além dos coeficientes de reação verticais, podem ser definidos coeficientes de reação horizontais e de rotação, seguindo o mesmo raciocínio. A Hipótese de Winkler não leva em consideração a interação entre áreas carregadas adjacentes, ou seja, os coeficientes de reações verticais são independentes entre si. O coeficiente de reação vertical depende de diversos fatores, dentre eles as dimensões da fundação e o tipo de construção, não constituindo uma propriedade do solo, e pode ser determinado por meio de tabelas típicas e correlações com as propriedades elásticas do solo, por ensaio, ou pelo recalque estimado utilizando a Equação 1 e as Equações 2 e 3.

$$
\begin{gathered}
w=p B\left(\frac{1-v^{2}}{E}\right) I_{p} \quad \text { Equação } 2 \\
k_{v}=\left(\frac{E}{1-\vartheta^{2}}\right) \frac{B}{I_{p}} \quad \text { Equação } 3
\end{gathered}
$$

Onde:

$w$ : recalque.

$p$ : carregamento imposto.

B: menor largura da sapata.

v: coeficiente de Poisson do solo. 
E: módulo de elasticidade do solo.

$I_{p}:$ fator de influência.

$k_{v}$ : coeficiente de recalque vertical.

Portanto, as características do solo pertinentes ao estudo são o coeficiente de Poisson e o módulo de elasticidade do solo, assim como as dimensões das sapatas e o fator de influência. Pode-se notar que para a determinação do recalque, se faz necessário conhecer o valor do carregamento e vice-versa. Porém, ao calcular um determinado deslocamento, ocorrerá uma redistribuição dos esforços, alterando o carregamento, logo trata-se de um processo iterativo.

Segundo Antoniazzi (2011), o mecanismo de interação solo-estrutura tem início juntamente com a fase inicial da construção e se estende até que haja uma situação de equilíbrio, ou seja, quando as deformações na estrutura e no solo estiverem estabilizadas. A compatibilização das deformações, tanto do solo quanto da superestrutura, resulta em uma tendência de uniformização de recalques.

Portanto, a determinação do recalque provém de um cálculo iterativo, que pode ser solucionado utilizando programas computacionais específicos.

Alguns efeitos sobre a distribuição de esforços em edifícios de concreto armado já foram obtidos por Antoniazzi (2011), que fez a análise de um pórtico plano de 12 pavimentos em concreto armado, com fundações do tipo sapata, sendo o solo classificado como argila arenosa e utilizando o método de Winkler. Comparando os resultados com a ISE e sem, obteve deslocamento até $74 \%$ maiores no primeiro pavimento ao considerar a ISE. Em se tratando de momentos fletores positivos, para as vigas do segundo tramo, os valores obtidos com a ISE foram entre $88 \%$ e $196 \%$ maiores, sendo o extremo superior alcançado junto à base do edifício. Nos últimos pavimentos, houve a inversão do sinal dos momentos fletores. Além disso, os esforços normais foram redistribuídos de forma que houve alívio nos pilares centrais e sobrecarregar nos pilares das extremidades, que experimentaram acréscimos de carga de até $18 \%$.

Resultados semelhantes foram obtidos por Mendonça et al. (2015) em uma análise de um edifício de quatro pavimentos, utilizando o modelo de Winkler. Além da análise 
dos esforços e deslocamentos com e sem a consideração da ISE, seu estudo comparou os resultados obtidos em diferentes tipos de solo e concluiu que a diferença é maior em solos argilosos e silte-argilosos, diminuindo na medida em que aumenta a sua consistência ou a compacidade dos solos arenosos.

Na pesquisa bibliográfica inicial não foram encontrados trabalhos sobre a análise do efeito da interação solo estruturas em edifícios estruturados em aço ou mistos de aço e concreto. Portanto, tem-se como objetivo analisar os efeitos da interação soloestrutura na distribuição de esforços e deslocamentos em estruturas metálicas sobre fundação superficial variando-se o número de pavimentos.

\section{Metodologia}

Para análise do efeito da interação solo-estrutura tomou-se como base um edifício modelo de uso residencial de múltiplos pavimentos estruturado em aço. São edificações hipotéticas e considerando um solo que, a princípio, teria capacidade para suportar fundações superficiais. A solução em fundação superficial não necessariamente é a solução mais adequada para algumas das configurações estudadas, porém servem de referência para futuros estudos considerando fundações profundas. As Figuras 3, 4 e 5 apresentam as plantas juntamente com a disposição dos contraventamentos adotados para cada uma das estruturas analisadas. As estruturas foram analisadas e dimensionadas sem e com a consideração da interação soloestrutura, variando-se a altura do edifício considerando cinco casos: 4, 8, 12, 16 e 20 pavimentos. Para viabilizar o aumento do número de pavimentos, houve a necessidade de variação dos contraventamentos (foram utilizados pórticos rígidos e tirantes dispostos em "X"). O aço utilizado foi o ASTM A572 Gr50 em perfis soldados e laminados nas vigas e pilares. Nas lajes e fundações foi utilizado concreto C20. A determinação das ações e combinações, a análise estrutural e o dimensionamento dos elementos estruturais em aço foram desenvolvidos de acordo com a NBR 8800 (ABNT, 2008). Para o projeto das fundações foram utilizadas as recomendações da NBR 6122 (ABNT, 2010). Além dessas, outras referências normativas foram utilizadas para projeto NBR 6123 (ABNT, 1988) referente às forças de vento em edificações e NBR 8681 (ABNT, 2003) referente às ações e segurança nas estruturas. Os coeficientes de 
reação vertical (CRV), que foram utilizados para a modelagem do solo-fundação, foram determinados por meio da Hipótese de Winkler.

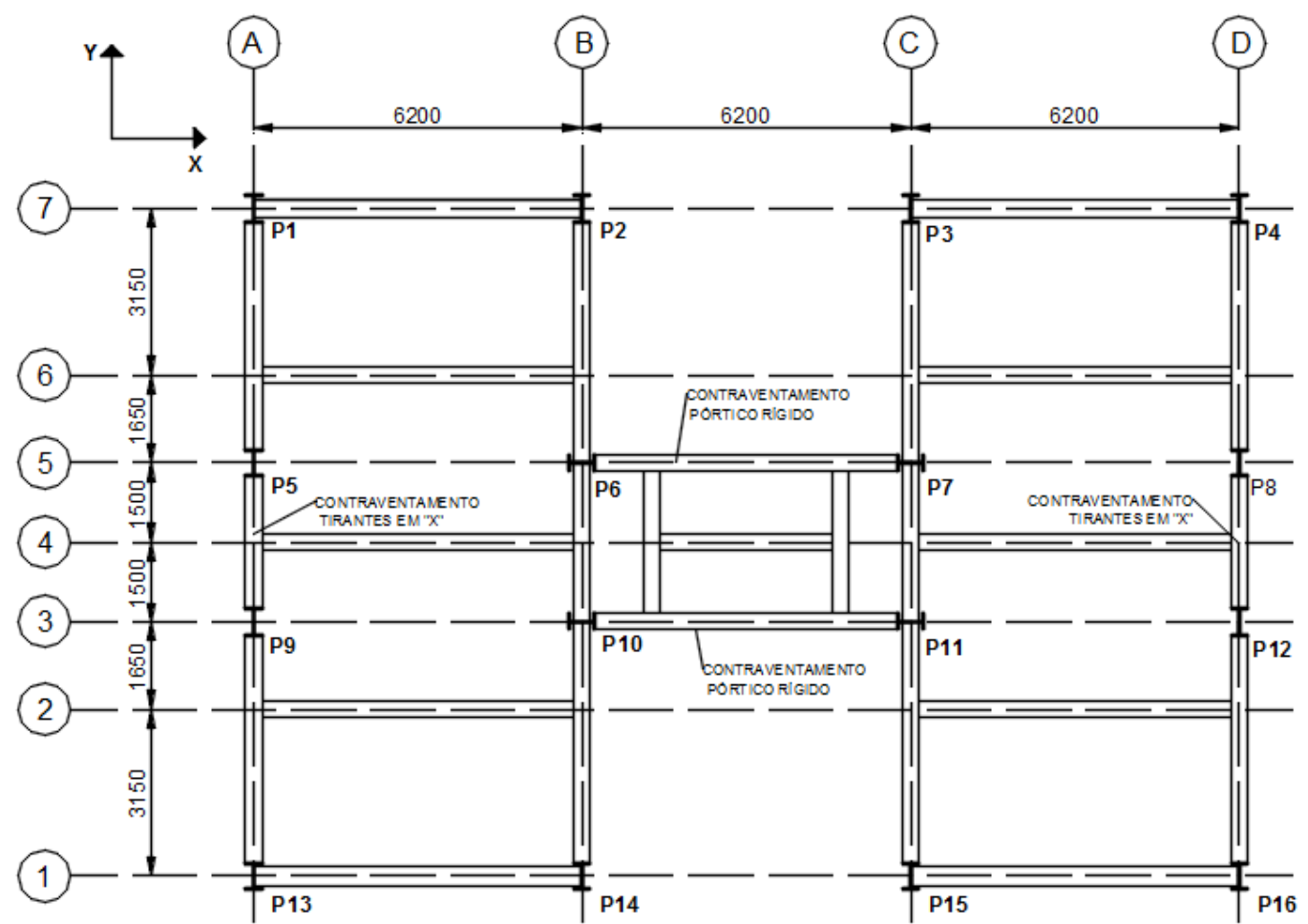

Figura 3 - Planta das edificações de 4 e 8 pavimentos (dimensões em mm)

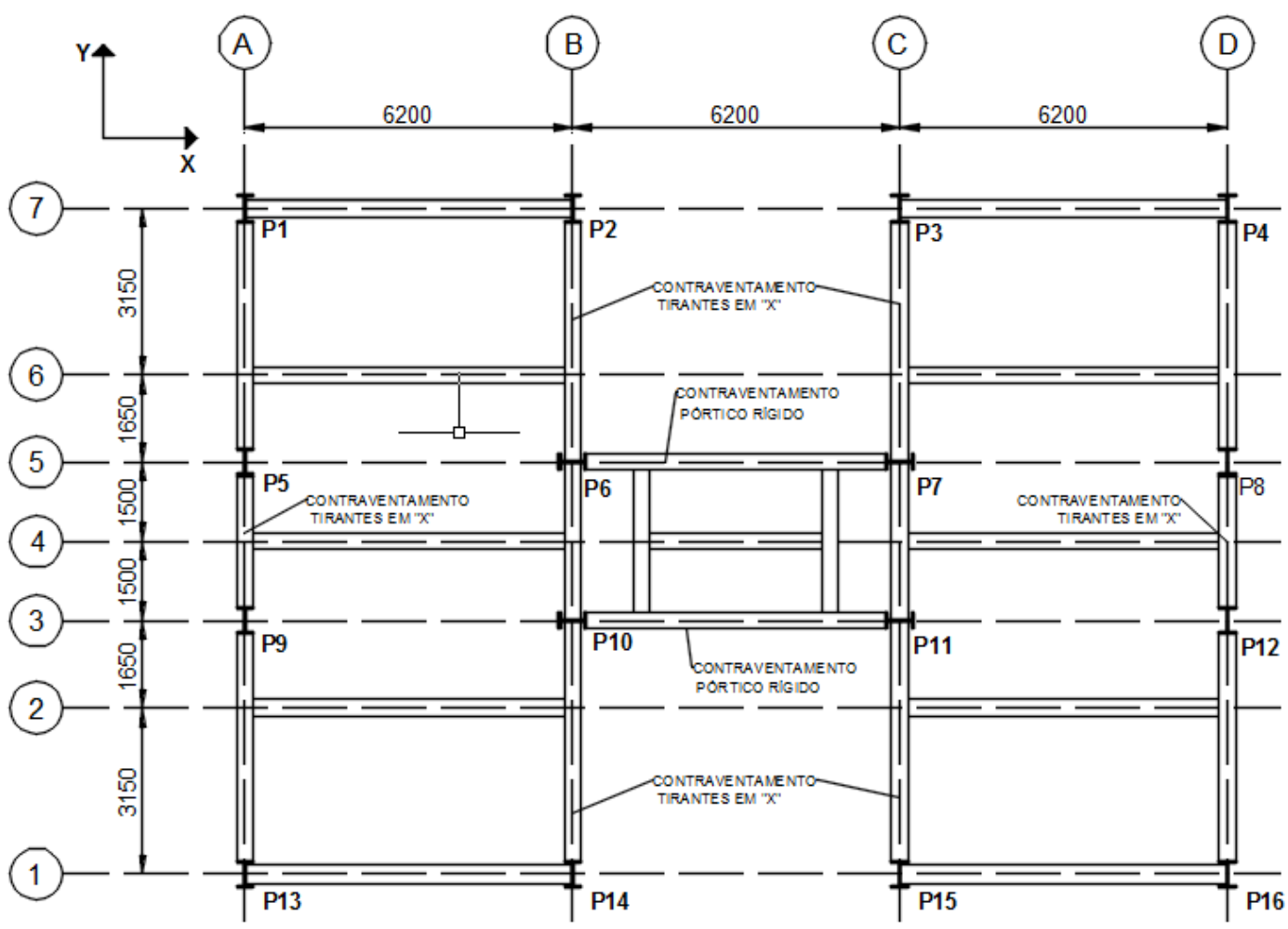

Figura 4 - Planta das edificações de 12 e 16 pavimentos (dimensões em mm) 


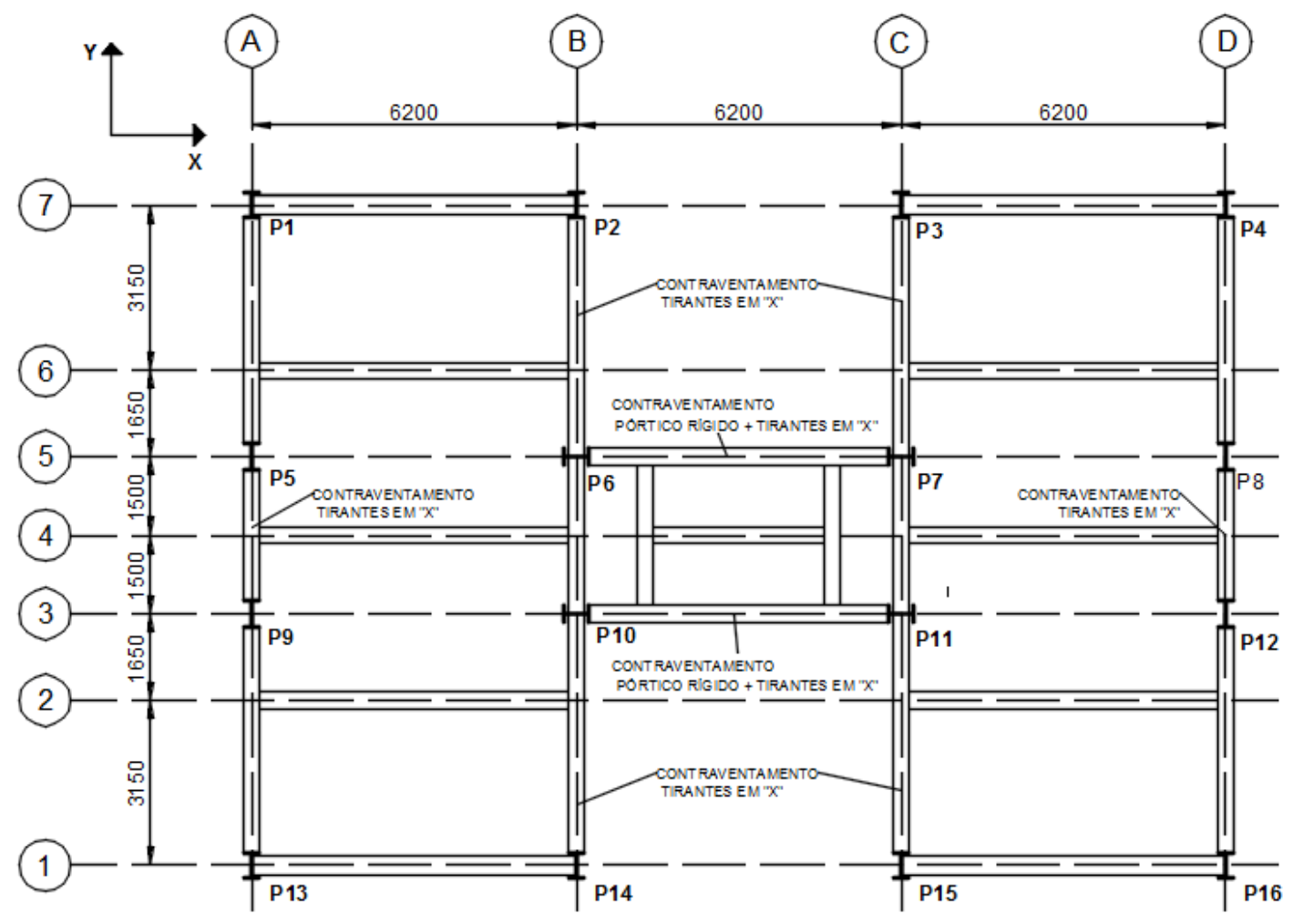

Figura 5 - Planta da edificação de 20 pavimentos (dimensões em $\mathrm{mm}$ )

A análise estrutural foi desenvolvida utilizando o programa SAP 2000 e de acordo com as recomendações da NBR 8800 (ABNT, 2008). A estrutura foi modelada tridimensionalmente incluindo a laje de concreto. A Figura 6 apresenta uma ilustração 3D da geometria do modelo estrutural e a discretização de um pavimento.
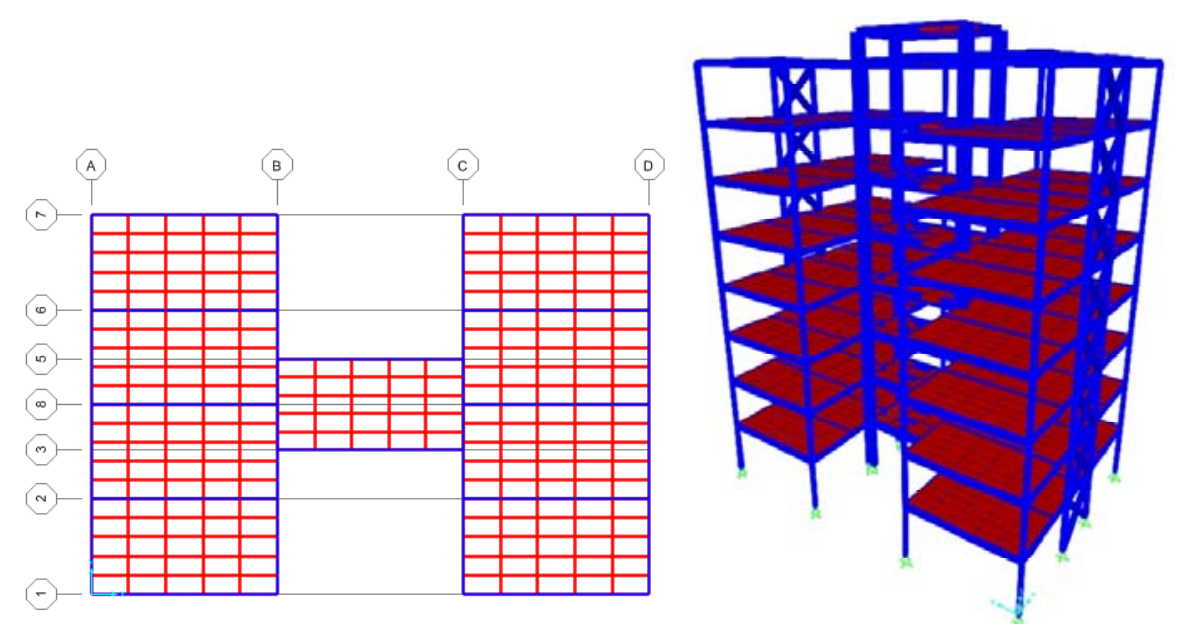

Figura 6 - Geometria do modelo estrutural

Uma vez dimensionada a estrutura considerando o solo indeslocável foi desenvolvido o projeto das fundações para a reações de apoio resultantes, ou seja, sem interação solo-estrutura. 
Para o projeto das fundações em sapata foi considerado um solo arenoso com tensão admissível inicial de $533 \mathrm{kN} / \mathrm{m}^{2}$, obtida através da equação 4 para o solo adotado, cujo perfil de sondagem SPT é apresentada na Figura 7. As sapatas foram consideradas assentadas na cota de $2 \mathrm{~m}$ cujo SPT é igual a 16. Estes valores foram adotados para estimativa inicial da tensão admissível do solo, já que neste momento não é conhecida ainda a profundidade do bulbo de tensões do solo abaixo da sapata.

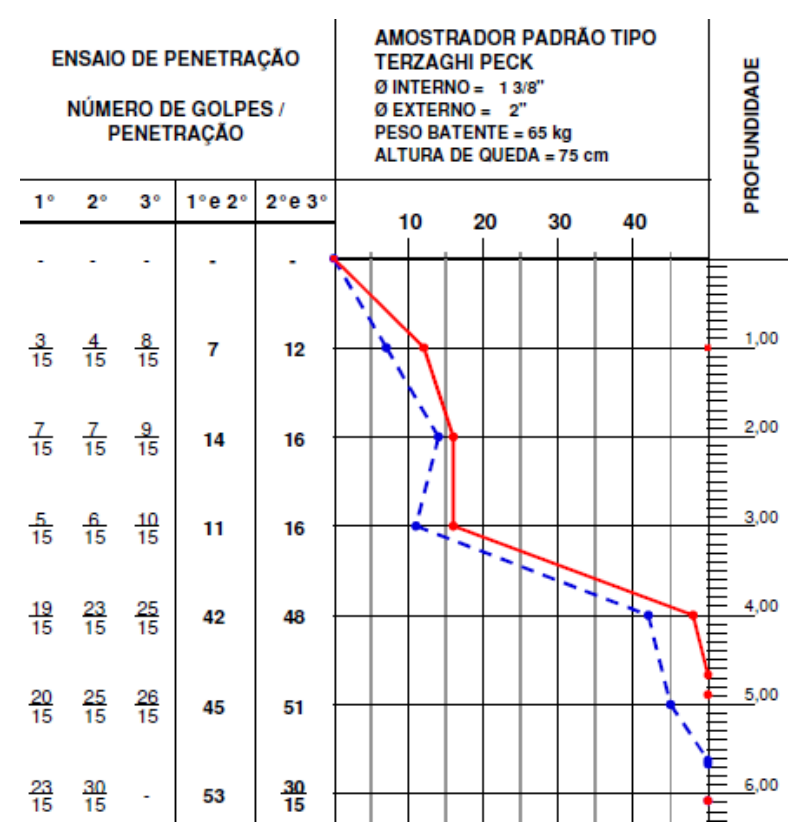

Figura 7 - Sondagem do solo utilizado.

$$
\sigma_{a d m}=\frac{N_{s p t}}{0,03} \quad \text { Equação } 4
$$

O módulo de elasticidade do solo, utilizado para o cálculo do recalque da fundação, foi obtido utilizando-se a Equação 5, apresentada em Godoy e Teixeira (1996).

$$
E_{s}=\alpha \cdot K \cdot N \text { Equação } 5
$$

Onde:

$\alpha$ : igual a 3 para solos arenosos

$K$ : igual a $900 \mathrm{kN} / \mathrm{m}^{2}$ para solos arenosos

$\mathrm{N}$ : Valor de SPT na camada de assente da fundação

Para o edifício de 4 pavimentos foram dimensionados três tipos diferentes de sapatas, para pilares com até 294 kN de compressão, outro tipo para pilares com até $508 \mathrm{kN}$ de compressão e, por fim, um outro tipo para pilares com até 668 kN de compressão. 0 mesmo procedimento foi adotado para todas as estruturas estudadas. A Figura 8 
apresenta a planta de fundação com as dimensões da sapata para o caso do edifício de 4 pavimentos.

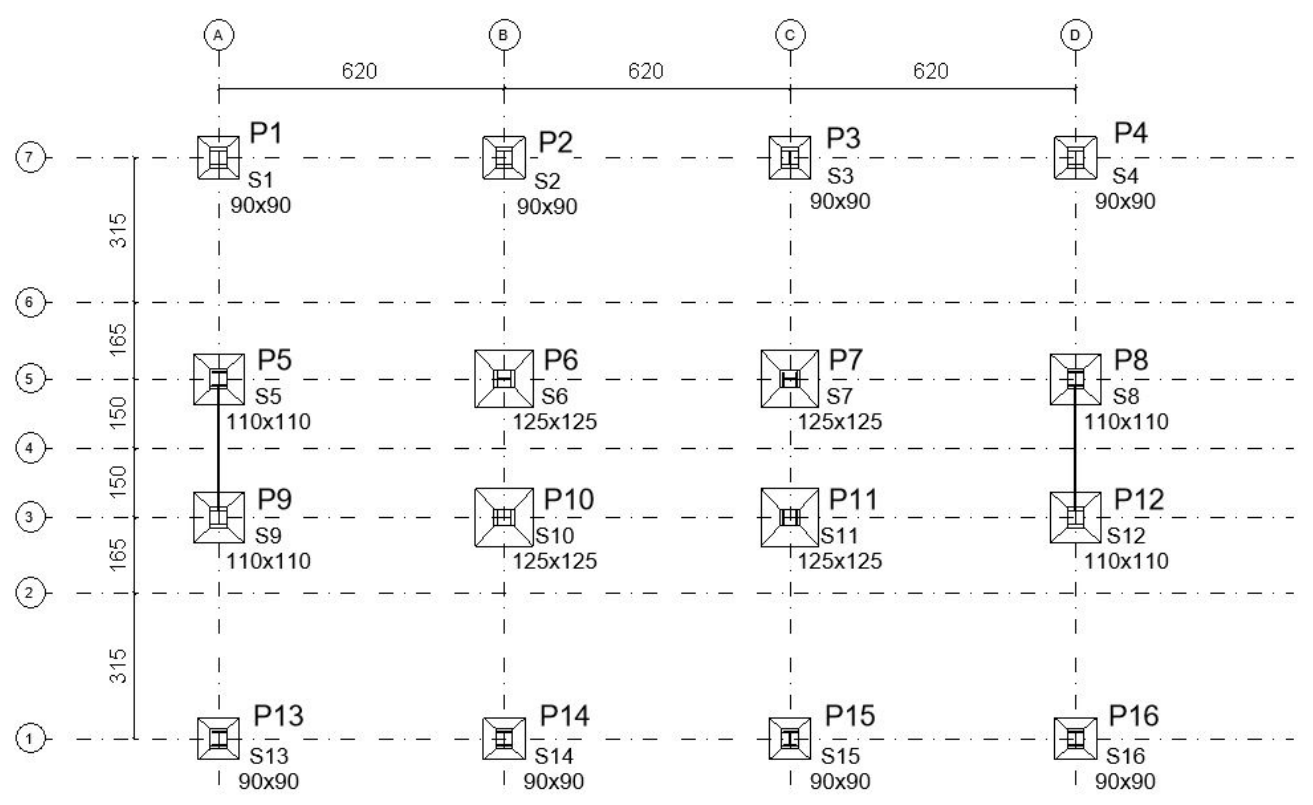

Figura 8 - Planta de fundação para o edifício com 4 pavimentos (cotas em $\mathrm{cm}$ ).

Concluído o projeto das estruturas e fundações passa-se a consideração da interação solo-estrutura. Para a análise considerando a interação solo estrutura (ISE) foram modeladas as estruturas com elementos de barras para vigas e pilares e elementos de placa para as lajes. As sapatas foram modeladas com elementos sólidos. E o solo foi representado no modelo de análise por molas verticais e horizontais determinadas de forma iterativa pelo processo de Winkler. A Figura 9 apresenta um detalhe do modelo numérico da estrutura e seus componentes, estrutura, sapatas, solo (representado pelas molas) para consideração da ISE.

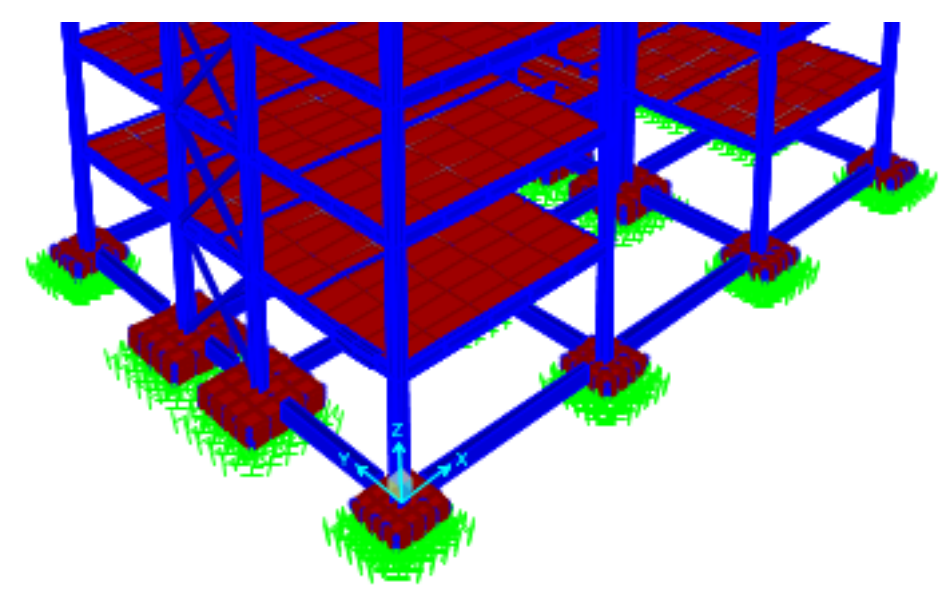

Figura 9 - detalhe do modelo estrutural para consideração da ISE. 
No modelo numérico os pilares estão conectados diretamente às fundações em sapatas. As sapatas foram modeladas com elementos finitos sólidos com uma malha regular que resultou em 25 nós em sua base. Os coeficientes de reação vertical obtidos para cada pilar, que no modelo representa o solo, foram distribuídos na área da sapata e aplicado nestes 25 nós. Procedimento semelhante foi adotado para aplicação dos coeficientes de reação horizontal.

\section{Resultados e discussões}

Apresenta-se e discute-se em seguida os resultados de recalques, deslocamentos e esforços com e sem a consideração da interação solo-estrutura para os 5 edifícios analisados. Foi adotada a seguinte nomenclatura ENpav ( $E$ = edifício e Npav - número de pavimentos) para identificar os modelos sem interação solo estrutura e para os modelos como interação solo estrutura ENpavISE. A Tabela 1 apresenta os coeficientes de reação vertical (CRV) obtido para os 5 casos analisados. Para os coeficientes de reação horizontal foram tomados valores correspondentes a $40 \%$ dos CRVs.

Tabela 1 - coeficientes de reação vertical

\begin{tabular}{|c|c|c|c|c|c|}
\hline & \multicolumn{5}{|c|}{ Coeficientes de reação vertical (kN/m) } \\
\hline Pilar & E4ISE & E8ISE & E12ISE & E16ISE & E20ISE \\
\hline 1 & 49390 & 76437 & 149125 & 128556 & 133364 \\
\hline 2 & 49390 & 76437 & 176545 & 134158 & 137476 \\
\hline 3 & 49390 & 76437 & 177545 & 133842 & 137476 \\
\hline 4 & 49390 & 76437 & 149250 & 126278 & 133318 \\
\hline 5 & 60366 & 111716 & 172091 & 124737 & 138520 \\
\hline 6 & 68598 & 111716 & 221385 & 175185 & 168978 \\
\hline 7 & 68598 & 111716 & 217154 & 175185 & 171435 \\
\hline 8 & 60366 & 111716 & 172091 & 124737 & 138560 \\
\hline 9 & 60366 & 111716 & 172091 & 124579 & 138560 \\
\hline 10 & 68598 & 111716 & 221462 & 175407 & 168978 \\
\hline 11 & 68598 & 111716 & 217231 & 175407 & 171435 \\
\hline 12 & 60366 & 111716 & 172091 & 124579 & 138560 \\
\hline 13 & 49390 & 76437 & 149000 & 128833 & 133364 \\
\hline 14 & 49390 & 76437 & 176182 & 133579 & 137476 \\
\hline 15 & 49390 & 76437 & 177545 & 133579 & 137476 \\
\hline 16 & 49390 & 76437 & 149125 & 126556 & 133182 \\
\hline & & & & & \\
\hline 12 & & & & & \\
\hline
\end{tabular}


Conforme o número de pavimentos aumenta, as dimensões das sapatas também aumentam, gerando CRVs que não dependem linearmente da altura da estrutura, mas sim da relação entre a força de compressão na base do pilar e as dimensões em planta da sapata.

O gráfico da Figura 10 apresenta uma comparação dos esforços de compressão na base dos pilares para análise convencional e considerando a ISE para a combinação de ações que conduz aos esforços críticos nos elementos estruturais.

Nota-se uma pequena redução nos valores dos esforços de compressão axial na base dos pilares centrais (P6, P7, P10 e P11), para todas as estruturas analisadas. Os pilares P13, P14, P15 e P16 (pilares que recebem a ação de vento para a combinação analisada), também apresentaram reduções dos valores destes esforços. A estrutura de 20 pavimentos apresentou redução dos esforços de compressão axial na base dos pilares centrais e aumento destes esforços nos pilares de extremidade. De forma qualitativa o comportamento é semelhante ao observado em estruturas de concreto armado com redução de esforços nos pilares centrais e aumento de esforços nos pilares periféricos.

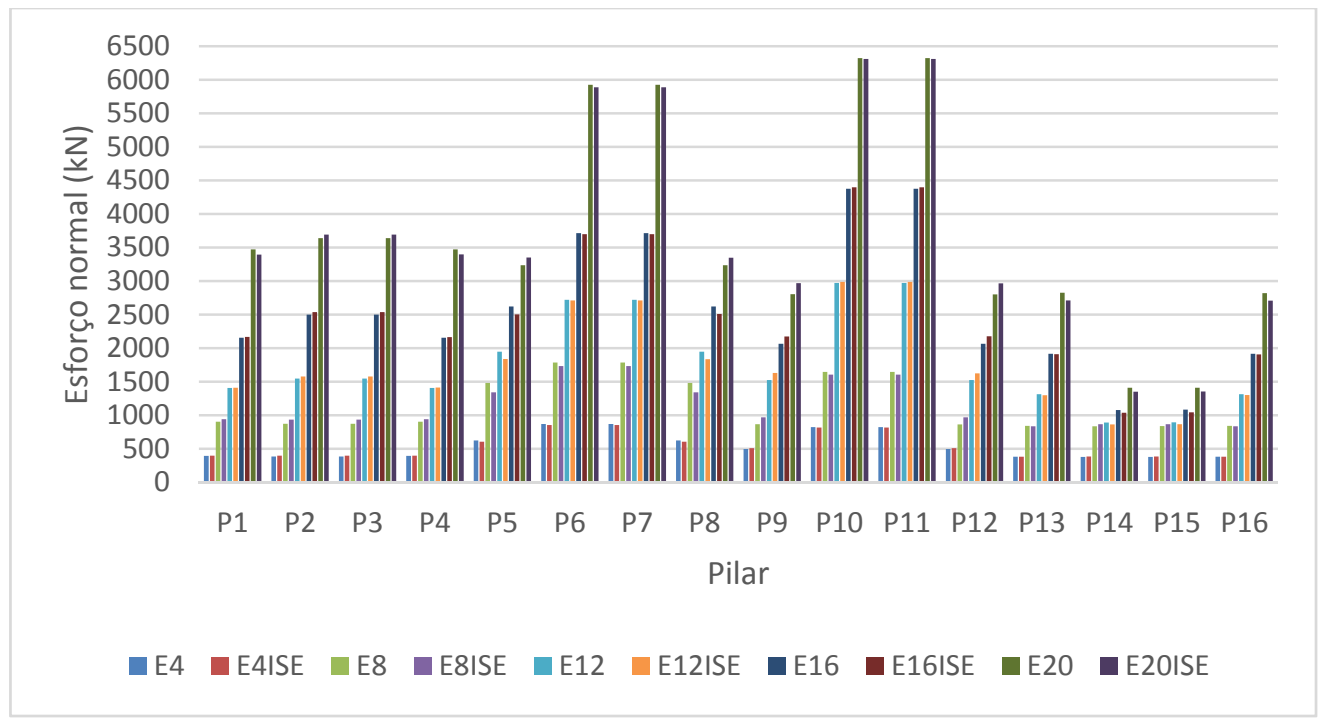

Figura 10 - Comparação de reações nos apoios com e sem ISE (kN)

O gráfico da Figura 11 apresenta uma comparação entre os recalques finais para análise convencional e considerando a ISE. 


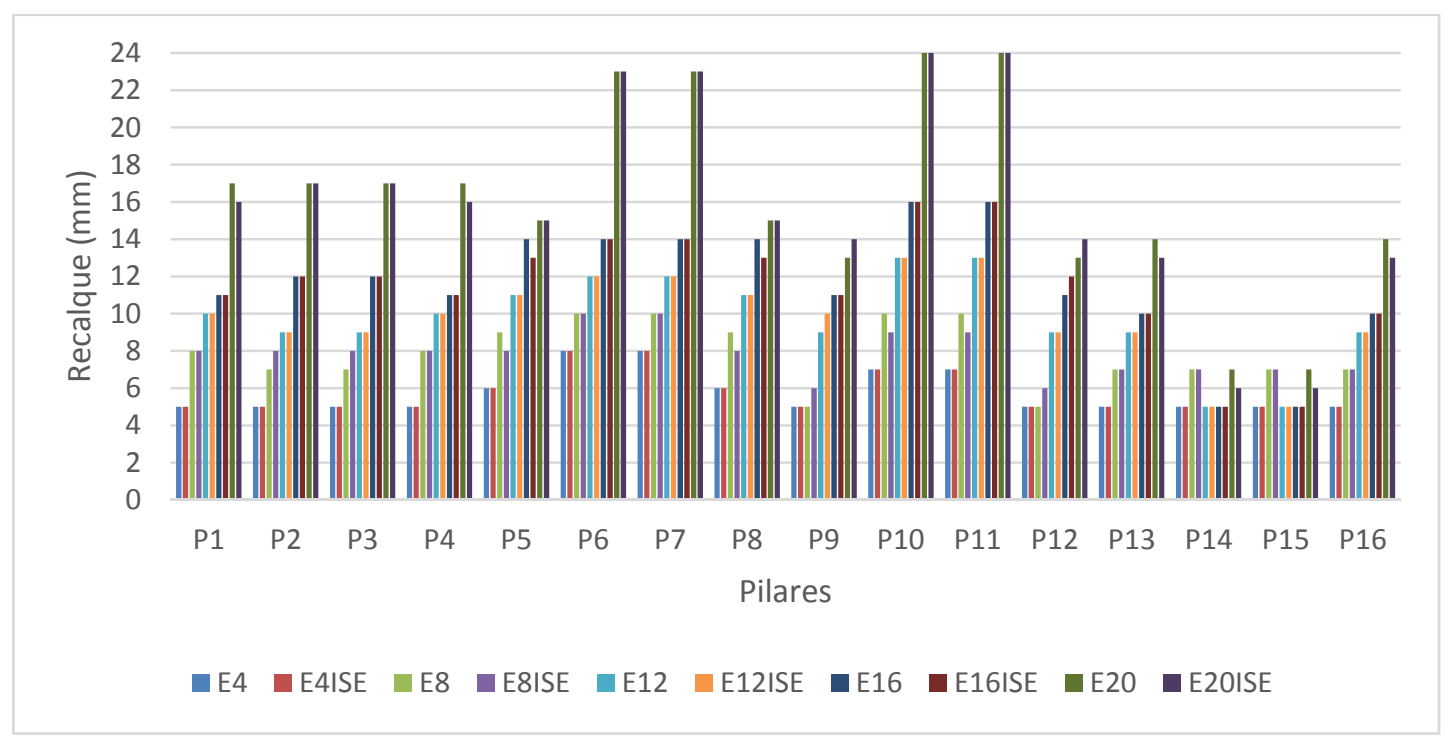

Figura 11 - Comparação de recalques com e sem ISE (mm)

Percebe-se pela Figura 11 que não houve alterações significativa dos recalques devido a análise considerando a ISE.

A Figura 12 apresenta de forma comparativa os momentos fletores finais nos apoios com e sem consideração da ISE.

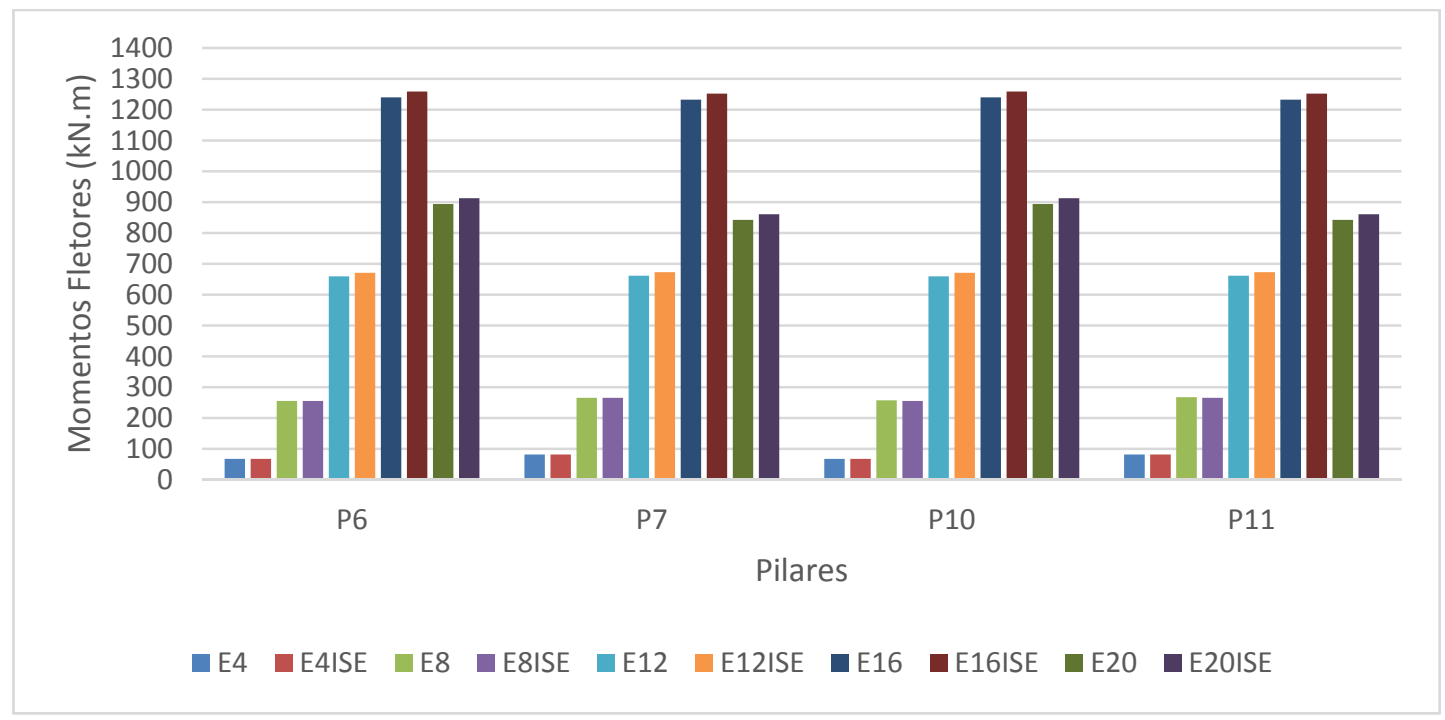

Figura 12 - Comparação dos momentos fletores com e sem ISE (kN.m)

Para as estruturas de até 8 pavimentos não houve variações significativas nos momentos fletores na base dos pilares. Já para as estruturas com 12 ou mais pavimentos houve um aumento nos momentos fletores, sendo este aumento de $1,67 \%$ para a estrutura de 12 pavimentos, 1,53\% para as estruturas de 16 e de $+2,12 \%$ para as estruturas de 20 pavimentos. 
Foram analisados também a variação dos esforços normais e momentos fletores ao longo da altura dos pilares. Para ilustrar esses resultados foi utilizado como exemplo o pilar P11 da estrutura de 20 pavimento.

A Tabela 2 apresenta os resultados de esforços axiais nos pilares ao longo da altura com e sem a consideração da iteração solo estruturas para o edifício de 20 pavimentos.

Tabela 2 - Variação do esforço de compressão axial ao longo da altura do pilar

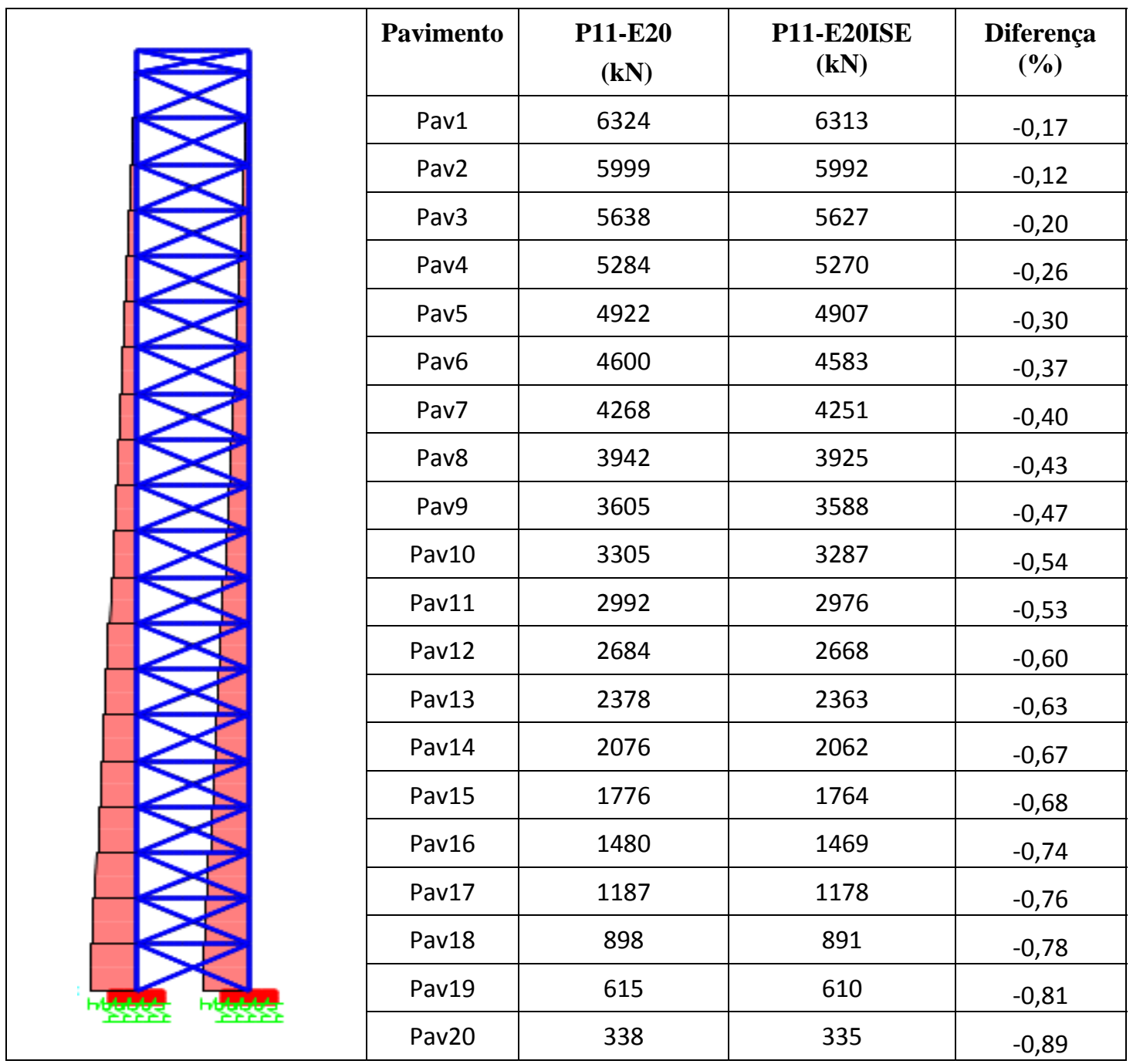

Observa-se que ocorrem maiores diferenças entre os esforços com e sem ISE para os pavimentos mais elevados, no entanto essa diferença não alcança 1\%. Para as demais estruturas esse comportamento é semelhante.

A Tabela 3 apresenta a variação dos momentos fletores ao longo da altura da edificação com e sem a consideração da iteração solo estrutura para o edifício de 20 pavimentos. 
Tabela 3 - Variação do momento fletor ao longo da altura do pilar

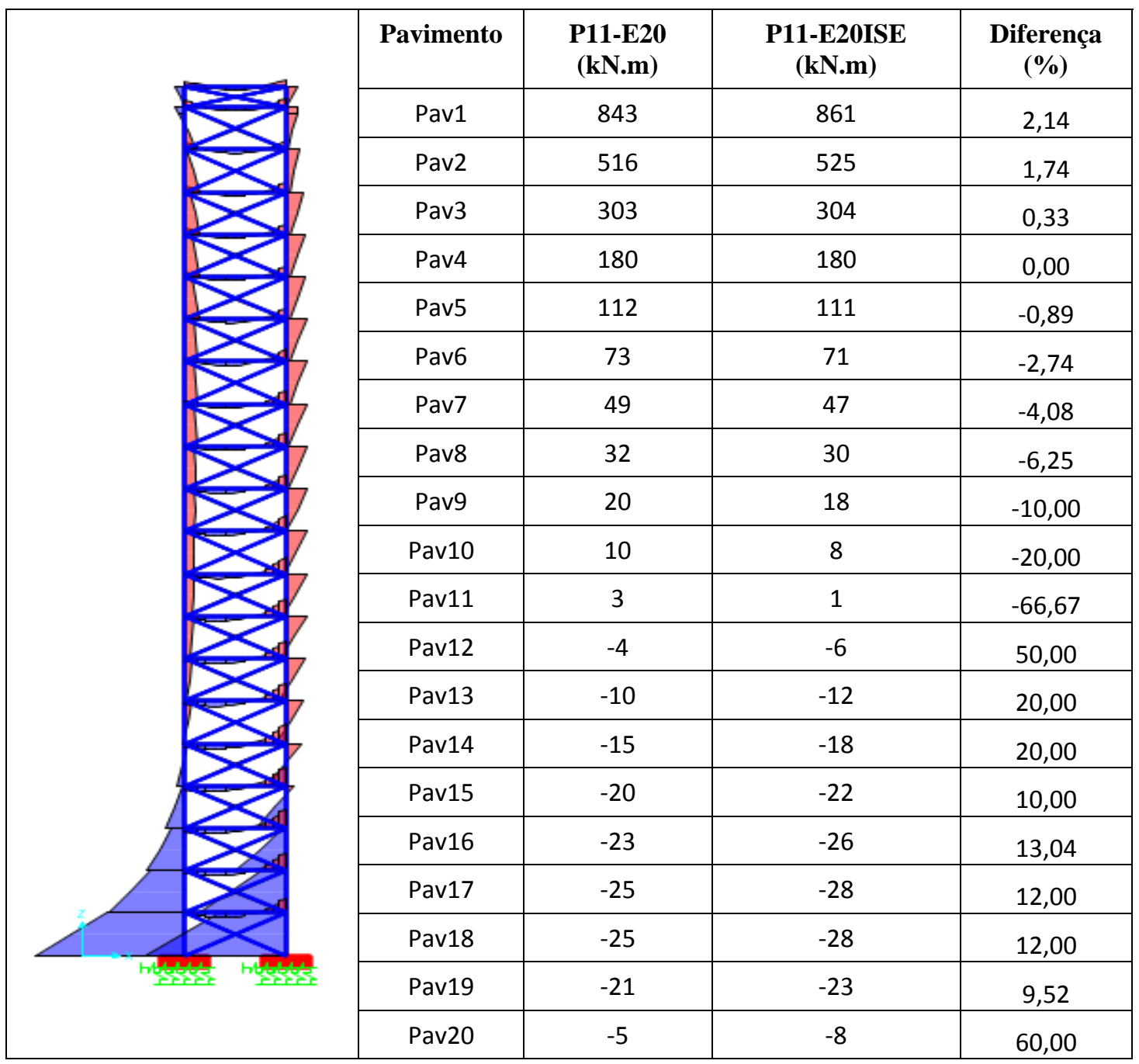

No caso apresentado a média das diferenças entre os momentos fletores com e sem a consideração da ISE é de 16\%. Para estruturas de aço, sobretudo as mais altas, já se esperava maiores diferenças nos resultados de momento fletor em relação aos esforços normais devido a relação entre as ações permanentes verticais e as ações horizontais do vento e a altura do edifício. Observa-se na Tabela 3 diferenças entre momentos fletores da ordem de $60 \%$, no entanto, isso ocorre para valores de momentos fletores muito pequeno visto que se trata de uma estrutura contraventada.

Com relação aos deslocamentos laterais as Figuras de 13 a 15 apresentam uma comparação entre os deslocamentos laterais para análise convencional e considerando a ISE para combinações de serviço. 

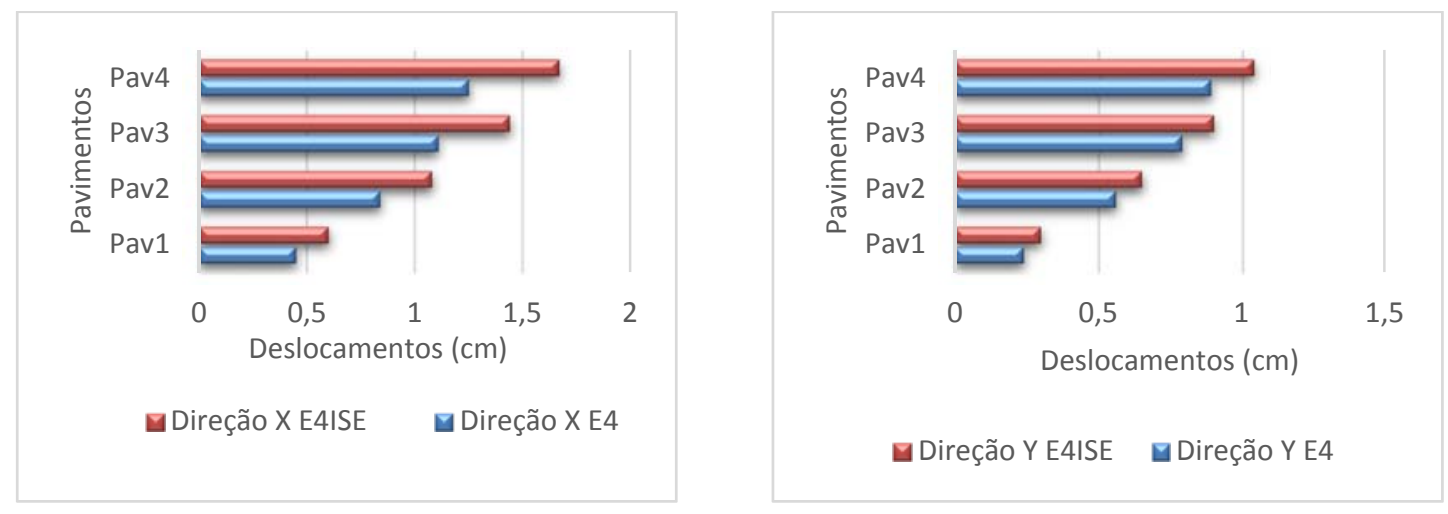

Figura 13 - Comparação deslocamentos laterais - Estrutura de 4 pavimentos

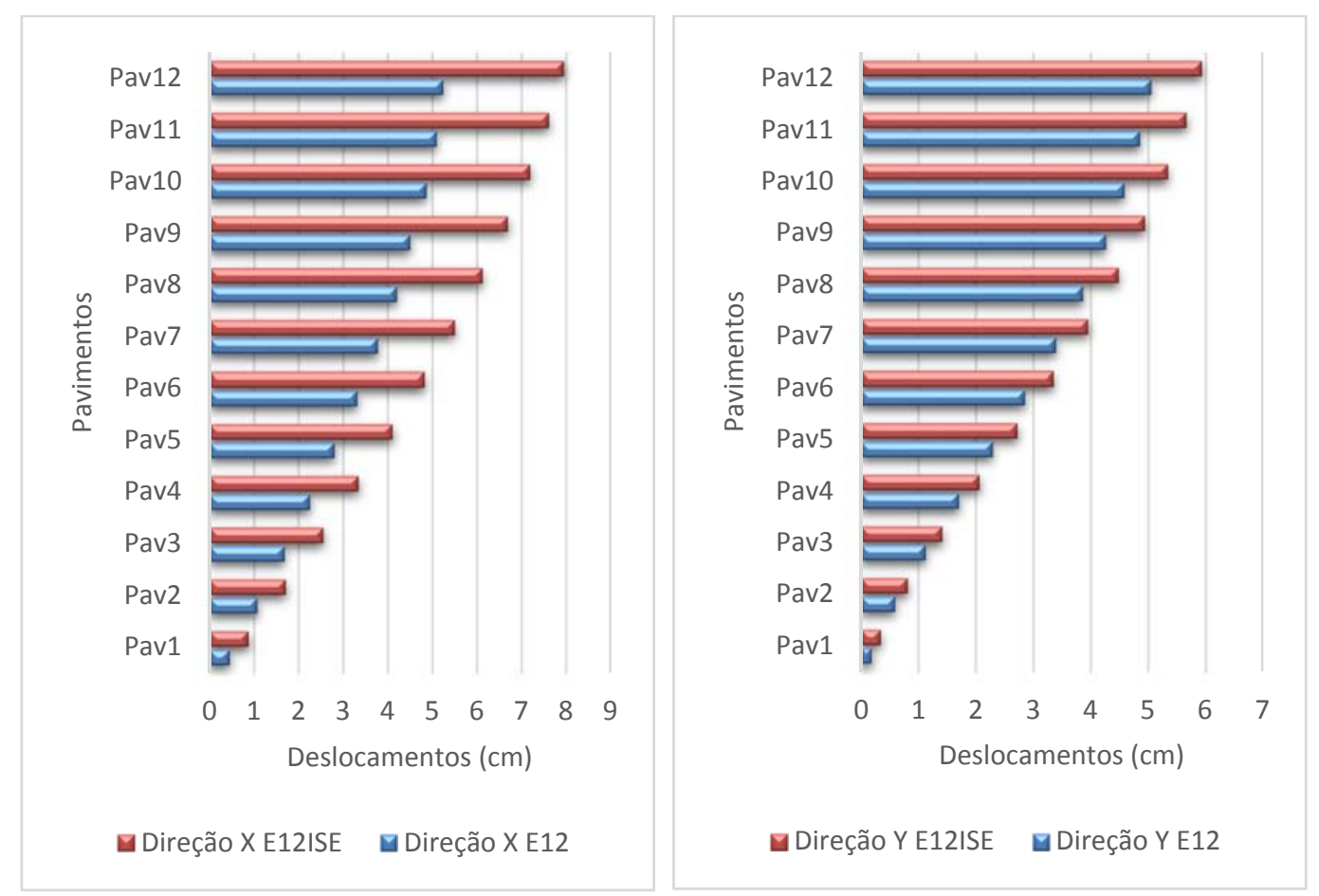

Figura 14 - Comparação deslocamentos laterais - Estrutura de 12 pavimentos 


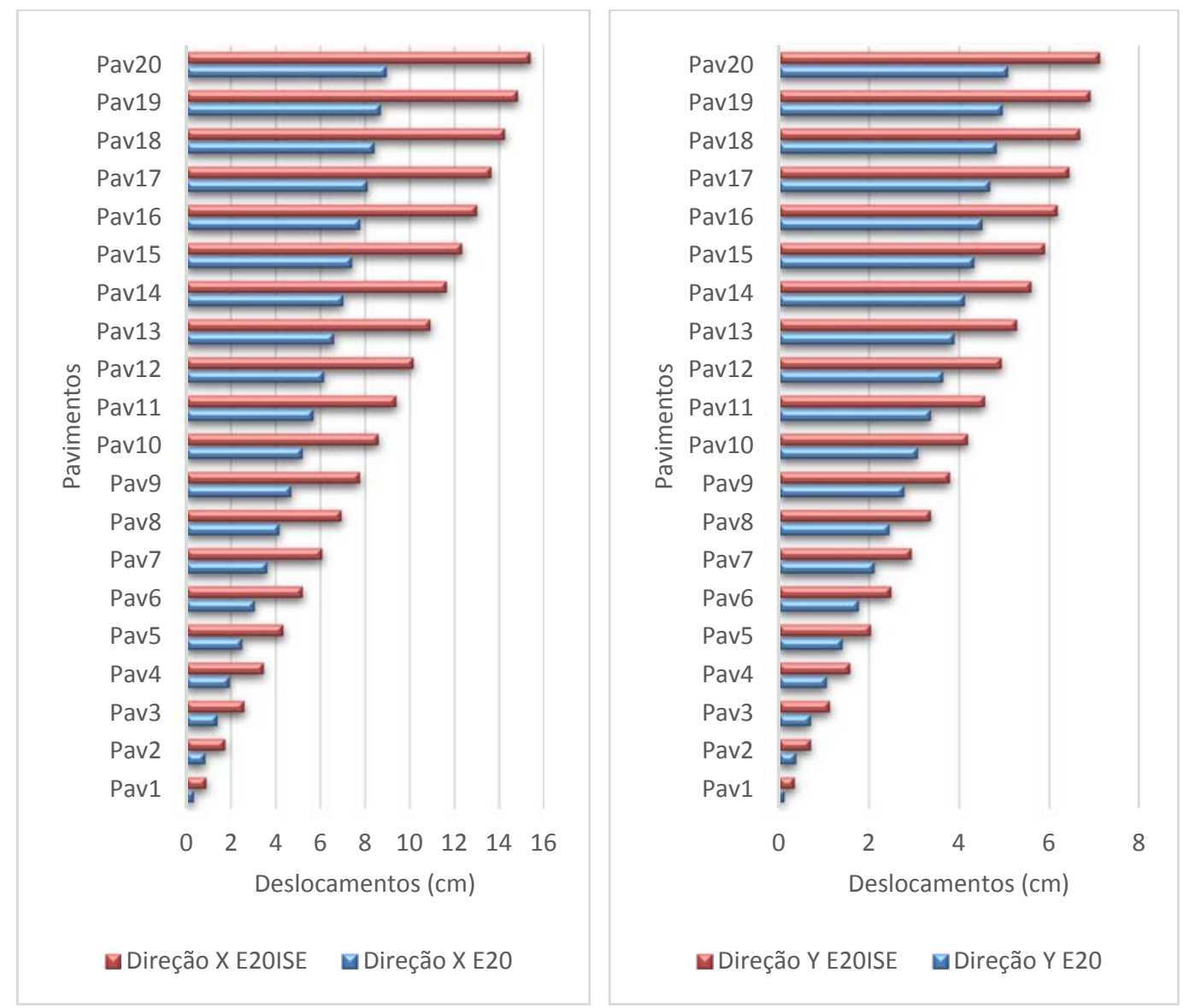

Figura 15 - Comparação deslocamentos laterais - Estrutura de 20 pavimentos

Para a estrutura de 4 pavimentos a variação do deslocamento no topo da estrutura foi de aproximadamente $33 \%$. As diferenças entre os deslocamentos com e sem ISE aumenta com o aumento no número de pavimentos chegando-se a $67 \%$ para a estrutura de 8 pavimentos e $72 \%$ para a estrutura de 20 pavimentos. Deve-se levar em consideração que houve alterações nos contraventamentos para viabilizar o aumento do número de pavimentos das estruturas, portanto não são estruturas exatamente idênticas no que se refere ao sistema de contraventamento.

A Figura 16 apresenta uma comparação para a variação ao longo da altura do coeficiente de classificação quanto a deslocabilidade " $\mathrm{B}_{2}$ ", no caso dos edifícios de 20 pavimentos, para análise convencional e considerando a ISE. A Figura 17 apresenta os valores máximos de $B_{2}$ utilizados para classificar cada estrutura quanto a deslocabilidade. 

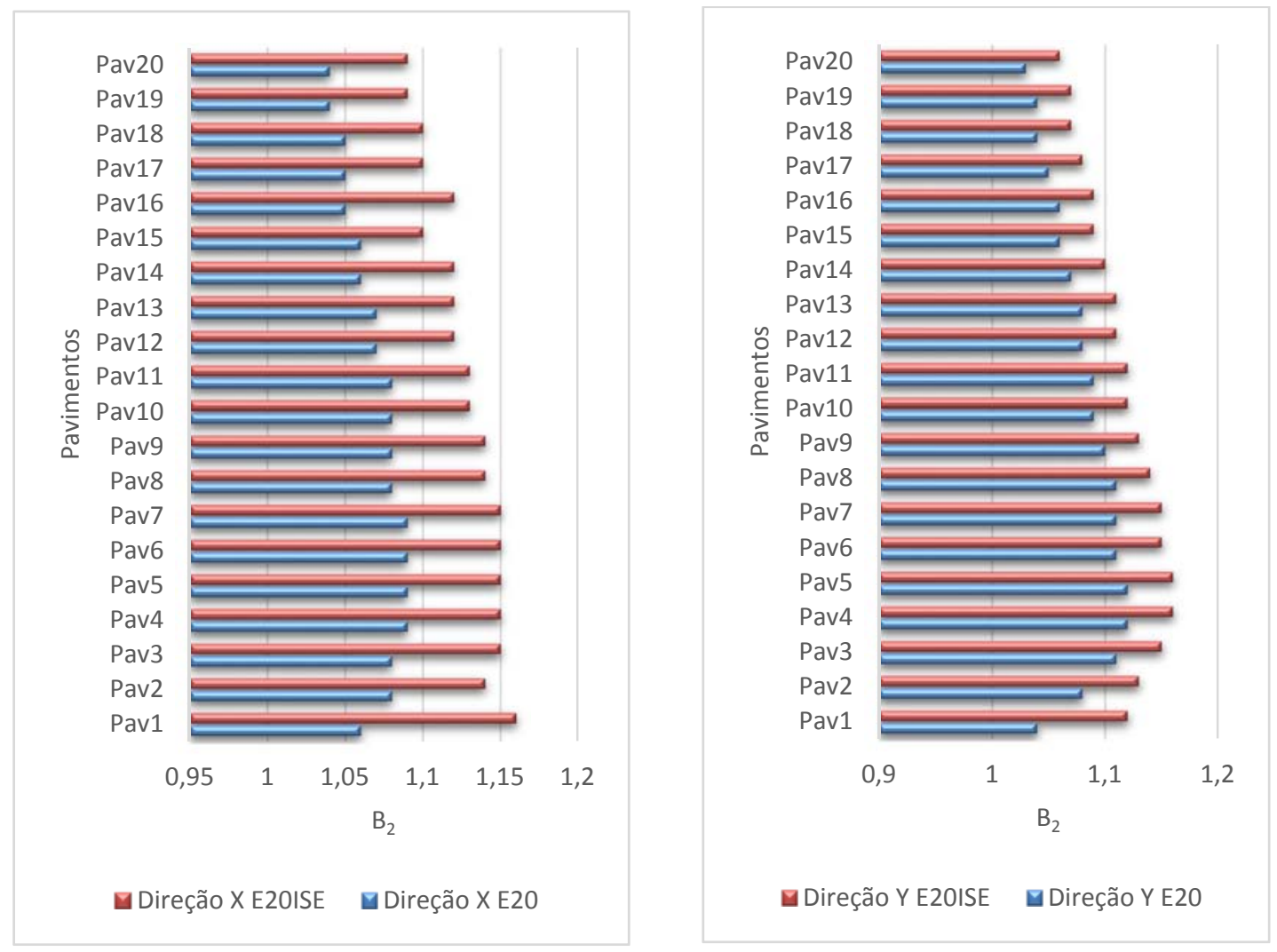

Figura 16 - Comparação dos coeficientes de estabilidade global - Estrutura 20 Pav.
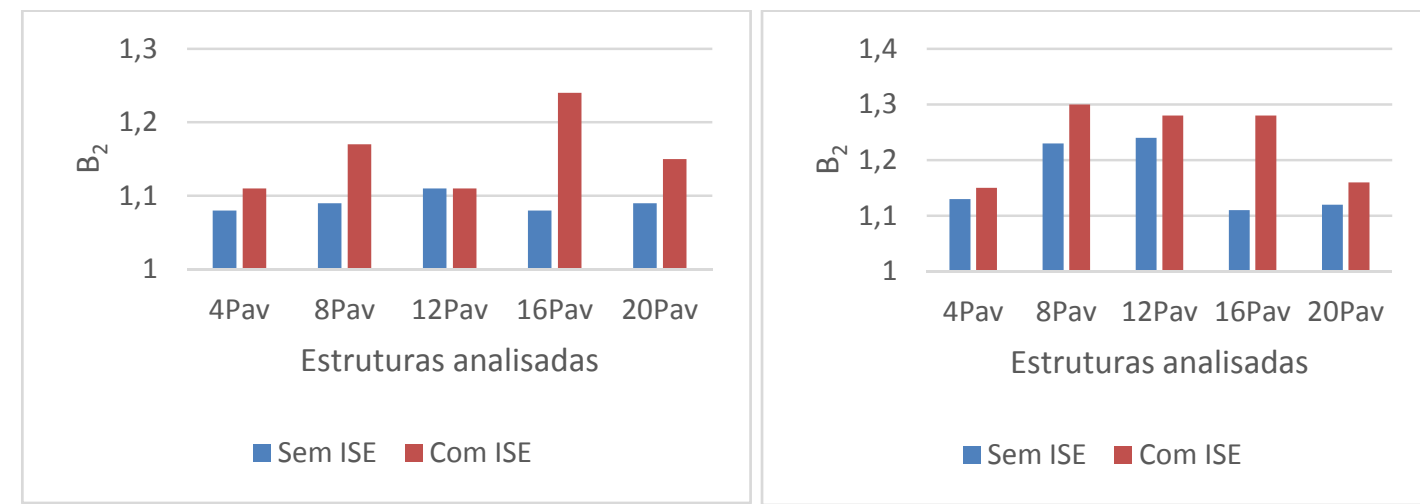

Figura 17 - Comparação dos coeficientes de estabilidade global - Direção "X"

Observou-se alterações significativas no coeficiente $B_{2}$ com a introdução da ISE na análise estrutural, sobretudo para os edifícios de maior altura. Para as estruturas de 8, 16 e 20 pavimentos houve, inclusive, mudança da classificação quanto a deslocabilidade de "pequena deslocabilidade" para "média deslocabilidade". A mudança de classificação da estrutura quanto a deslocabilidade acarretaria na necessidade de procedimentos de análise mais rigorosos no que se refere a consideração das imperfeições geométricas e de material. 


\section{Conclusões}

Este trabalho teve como objetivo iniciar os estudos da interação solo estrutura em estruturas metálicas cujos efeitos podem ser diferentes dos obtidos em estruturas de concreto armado. A consideração da ISE é um refinamento do modelo estrutural, onde a consideração da deformabilidade do solo se aproxima mais de uma estrutura real.

Pelos resultados expostos foi observado, de forma sutil, a tendência à redistribuição de esforços onde há o alívio dos pilares centrais e a sobrecarga dos pilares de extremidade, resultados que estão de acordo com os encontrados na literatura para estruturas de concreto armado. Porém os esforços de reação na base dos pilares, momentos fletores e recalques sofreram variações pouco significativas, possivelmente devido à leveza das estruturas metálicas. Os deslocamentos laterais, por sua vez, apresentaram variações significativas, possivelmente devido a melhor representação da vinculação do pilar tendo sido incluídos no modelo a sapata e o solo, por meio de molas de rigidez, e não simplesmente o engastamento ideal. Os coeficientes de estabilidade global, $B_{2}$, também apresentaram variações significativas, onde inclusive houve alterações da classificação da estrutura metálica, passando de pequena para média deslocabilidade, o que implicaria em diferentes considerações na análise estrutural. Os esforços de compressão axial e de momentos fletores apresentaram variações constante ao longo da altura dos pilares, ou seja, a mesma taxa de variação encontrada na base dos pilares foi observada ao longo de toda a altura dos pilares. Portanto, observa-se que, nas estruturas analisadas, os deslocamentos laterais e os coeficientes de estabilidade global foram os mais afetados pela consideração da ISE na análise estrutural.

Este trabaho utilizou o modelo de Winkle que embora conduza a resultados satisfatórios é um modelo simplificado e pode ser utilizado para avaliar o comportamento da estrutura para uma gama de variação nos coenficientes verticais. E uma evolução natural do modelo é a representação do solo como um meio contínuo e a consideração da sequência construtiva na avaliação dos recalques. 


\section{Referências bibliográficas}

ANTONIAZZI, J.P. Interação solo-estrutura de edifícios com fundações superficiais. 2011. 138 p. Dissertação (Mestrado em Engenharia Civil) - Centro de Tecnologia, Universidade Federal de Santa Maria, Santa Maria, 2011.

ANTONIAZZI, J.P.; ALVA, G.M.S.; SOARES, J.M.D. Procedimento para a consideração da interação solo-estrutura em edifícios com fundações em sapatas isoladas. In: CONGRESSO BRASILEIRO DO CONCRETO, 2010, Curitiba. Anais... Santa Maria, 2010. p. $1-16$.

ASSOCIAÇÃO BRASILEIRA DE NORMAS TÉCNICAS. ABNT NBR 8800 Projeto de estruturas de aço e de estruturas mistas de aço e concreto de edifícios. Rio de Janeiro. 2008.

ASSOCIAÇÃO BRASILEIRA DE NORMAS TÉCNICAS. ABNT NBR 6122 Projeto e execução de fundações. Rio de Janeiro. 2010

ASSOCIAÇÃO BRASILEIRA DE NORMAS TÉCNICAS. ABNT NBR 6123 Forças devidas ao vento em edificações. Rio de Janeiro. 1988

ASSOCIAÇÃO BRASILEIRA DE NORMAS TÉCNICAS. ABNT NBR 8681 Ações e segurança nas estruturas - Procedimento. Rio de Janeiro. 2003.

COLARES, G.M. Programa para análise da interação solo-estrutura no projeto de edifícios. 2006. 83 p. Dissertação (Mestrado em Engenharia de Estruturas) - Escola de Engenharia de São Carlos, Universidade de São Paulo, São Carlos, 2006.

CRESPO, V.A.S. Estudo da sensibilidade de edificações em relação ao solo. 2004. 108 p. Dissertação (Mestrado em Engenharia Civil) - Centro de Ciência e Tecnologia, Universidade Estadual do Norte Fluminense Darcy Ribeiro, Campos dos Goytacazes, 2004.

GODOY, N.S; TEIXEIRA, A. H. Análise, projeto e execução de fundações rasas. In: HACHICH et al. (eds.). Fundações: Teoria e prática. São Paulo: Pini. Cap. 7, p.227-264, 1996.

GONÇALVES, J. C. Avaliação da influência dos recalques das fundações na variação de cargas dos pilares de um edifício. 2014. Tese (Doutorado em Engenharia de Estruturas) - Universidade Federal do Rio de Janeiro, Rio de Janeiro, 2014.

GUSMÃO, A.D. Estudo da interação solo-estrutura e sua influência em recalques de edificações. 1990. 165 p. Tese (Mestrado em Ciências em Engenharia Civil) Universidade Federal do Rio de Janeiro, Rio de Janeiro, 1990.

HOLANDA JR, O.G. Interação solo-estrutura para edifícios de concreto armado sobre fundações diretas. 1998. 180 p. Dissertação (Mestrado em Engenharia de Estruturas) - Escola de Engenharia de São Carlos, Universidade de São Paulo, São Carlos, 1998.

IWAMOTO, R.K. Estrutura em edifícios de múltiplos andares com fundação profunda. 2000. 140 p. Dissertação (Mestrado em Engenharia de Estruturas) - Escola de Engenharia de São Carlos, Universidade de São Paulo, São Carlos, 2000.

MENDONÇA, F.R.S.; SILVA, J.G.S.; SIEIRA, A.C.C.F. Avaliação do efeito da interação soloestrutura sobre a resposta estrutural de edifícios mistos (aço-concreto). In: 
CONGRESSO DE MÉTOdOS NUMÉRICOS EM ENGENHARIA, 2015, Lisboa. Portugal: APMTAC, 2015. p. 1-20.

REIS, J. H. C. Interação solo-estrutura de grupo de edifícios com fundações superficiais em argila mole. 2000. Tese (Doutorado em Geotecnia) - Escola de Engenharia de São Carlos, Universidade de São Paulo, São Carlos, 2000.

SILVA, W. Q e CODA, H. B. Desenvolvimento de programa computacional para análise de edificações considerando a interação solo-estrutura em conjunto com o comportamento não linear geométrico In: 52 CONGRESSO NACIONAL DO CONCRETO. Fortaleza, 2010.

SILVA, W. Sobre análise não linear geométrica de edifícios considerando o empenamento dos núcleos estruturais e a interação solo-estrutura. 2014. Tese (Doutorado em Engenharia de Estruturas) - Escola de Engenharia de São Carlos, Universidade de São Paulo, São Carlos, 2014.

TESTONI, E. Análise estrutural de edifícios de paredes de concreto por meio de pórtico tridimensional sobre apoios elásticos. 2013. Dissertação (Mestrado em Engenharia de Estruturas) - Escola de Engenharia de São Carlos, Universidade de São Paulo, São Carlos, 2013. 